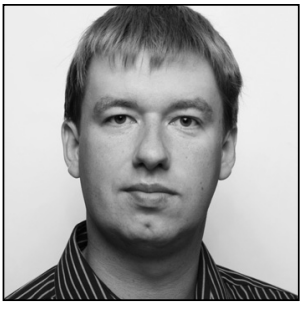

Kristjan Kask

$\mathrm{PhD}$

School of Natural Sciences and Health, Tallinn University

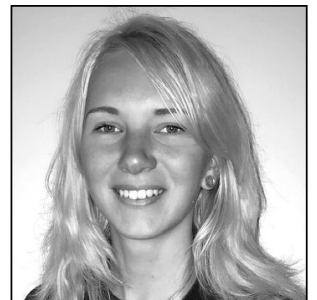

Liisa Tarkus

MA

School of Natural Sciences and Health, Tallinn University

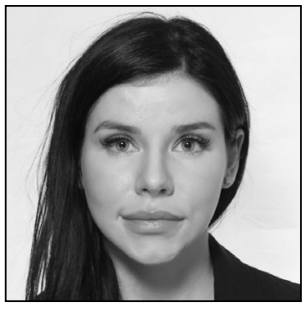

Alina Harkovskaja

$M A$

School of Law

University of Tartu

\title{
Identification of Provoked State in Estonian County Court Rulings of 2006-2016
}

\section{Introduction}

One of the main questions in forensic psychiatry and psychology related to the legal system is that of issues surrounding assessment of a defendant's mental state during commission of the crime. ${ }^{{ }^{*}}$ In Estonian legal literature, there has been debate on engagement of forensic psychology and psychiatry experts in identification of provoked state. ${ }^{{ }_{2}}$ However, the literature has not yet examined how that state is identified in the courts - i.e., to what extent experts are involved. Therefore, this paper has been prepared ${ }^{*} 3$ to investigate more closely how provoked state is identified in the judicial proceedings.

\subsection{Provoked state}

Sometimes a person cannot sufficiently control his or her behaviour because emotion regulation is inhibited. Affect in a very broad sense can be defined as any emotional reaction to external stimuli. ${ }^{4}$ In a narrower sense, affect is an emotional reaction to stimuli that is so extreme that the person's self-control is diminished or completely inhibited. ${ }^{*} 5$ From a legal perspective, this may lead to a question of whether the above has an effect on liability in the context of penal law. ${ }^{* 6}$

1 A. Aadamsoo. Süüdimatuse meditsiinilised tunnused ['Medical features of incapability of guilt']. - Juridica 2002/II, pp. 100-102 (in Estonian).

2 T. Kompus. Emotsionaalsete seisundite hindamine kohtupsühholoogilisel ekspertiisil ['Evaluating emotional statuses in forensic-psychology expert assessment']. - Juridica 2002/II, pp. 96-99 (in Estonian); P. Randma. Afekt kui hingelise erutuse seisund ja ajutine raske psüühikahäire ['Affect as highly provoked state and temporary severe mental disorder']. - Juridica 2005/V, pp. 321-331 (in Estonian); J. Saar, P. Pikamäe. Hingelise erutuse seisund. Probleemidest Eesti karistusõiguses ja kohtupraktikas ['Highly provoked state: Problems in Estonian penal law and practice']. - Juridica 2006/IX, pp. 591-600 (in Estonian).

3 The authors thank Lawrence T. White and Josephine Hirsch from the USA's Beloit College for their valuable comments during preparation of the paper and Sandra Kaasik of Tallinn University for assistance in coding the data.

4 For example, see J. Saar, P. Pikamäe (see Note 2).

5 T. Bachmann. Psühholoogia - raamat juristile ['Psychology - a Book for the Lawyer']. Tallinn: Juura 2015, especially pp. 176-184.

6 P. Randma (see Note 2). 
Under mitigating circumstances, homicide as dealt with under $§ 113$ of the Estonian Penal Code (PC) can be classified as manslaughter committed in a provoked state (PC \$115). ${ }^{*}$ The PC defines manslaughter in a provoked state as an act 'committed in a state of sudden extreme emotional disturbance caused by violence or insult inflicted on the killer or a person close to him or her by the victim'. This distinction is important from the standpoint of penal law because the crime in the absence of these circumstances is punishable by 6-15 years' imprisonment (under §113) while the sentence under $\$ 115$ is instead one to five years' imprisonment, thus making the difference in maximum sanctions 10 years.

In Germany ${ }^{*}$, provoked state is defined in a similar manner, with the German Penal Code ${ }^{*}$ identifying murder under mitigating circumstances (§213) as follows: when the murderer 'was provoked to rage by maltreatment inflicted on him or a relative, or was seriously insulted by the victim and immediately lost self-control and committed the offence, or in the event of an otherwise less serious case'.

In common-law countries, in contrast, the term 'heat of passion' or 'loss of control' is more commonly used. In the United States ${ }^{*} 10$, a homicide committed in the heat of passion may be qualified as manslaughter in the presence of several particular characteristics (i.e., when provocation occurred in which conditions a reasonable person, if exposed to said provocation, would have lost control; the defendant was indeed provoked and experienced, as a direct result, uncontrollable rage or other extreme emotional disturbance; the time that elapsed between the provocation and the homicide was not enough for a reasonable person to have 'cooled off'; and the defendant indeed did not cool off before killing the victim). ${ }^{* 11}$ For England and Wales, the Coroners and Justice Act ${ }^{* 12}$ defines loss of control in the following terms (in §54):

Where a person ('D') kills or is a party to the killing of another ('V'), D is not to be convicted of murder if -

(a) D's acts and omissions in doing or being a party to the killing resulted from D's loss of self-control,

(b) the loss of self-control had a qualifying trigger,

(c) and a person of D's sex and age [...] might have reacted in the same or in a similar way* 13

\subsection{Identification of provoked state}

The provoked state is initiated by the behaviour of the victim. ${ }^{* 14}$ Provoking behaviour can obtain in the form of non-verbal and/or verbal violence or insult directed toward the defendant and/or the defendant's relatives, and its existence is interpreted subjectively (still, the behaviour constituting the insult should be considered generally unlawful in the relevant society). It is known from cognitive psychology that the context does influence whether something said or done is interpreted as an insult. ${ }^{*} 15$ Accordingly, a person already in a provoked state may not be able to perceive the situation objectively, and, therefore, reactions can vary. ${ }^{*}{ }^{6}$ Although a person should be able to control him- or herself, it is easier to understand an

7 Penal Code (Karistusseadustik). - RT I, 23.12.2014, 16 (in Estonian).

8 For comparison of terminology in Estonian, German, and US law, see J. Saar. Kriminaalkorras karistatavate ja õiguspäraste surmamiste regulatsioon Eestis võrrelduna Ameerika Ühendriikide ja Saksamaa õigusega ['The regulation of homicide in Estonian, US, and German law']. - Juridica 2000/I, pp. 14-26 (in Estonian).

9 See the German Criminal Code, in the version promulgated on 13 November 1998 in the Bundesgesetzblatt (Federal Law Gazette) I, from para. 3322, last amended by Article 1 of the Law of 24 September 2013 (see Bundesgesetzblatt I, from para. 3671), and with the text of Section 6(18) of the Law of 10 October 2013 (see Bundesgesetzblatt I, from para. 3799), §1809. Available at http://www.gesetze-im-internet.de/englisch_stgb/englisch_stgb.html\#p1809 (most recently accessed on 15.1.2018). See also P. Randma (see Note 2).

10 American Law Institute. Model Penal Code Official Draft and Explanatory Notes (complete text of the model penal code as adopted at the 1962 annual meeting of the American Law Institute in Washington, DC, on 24 May 1962). American Law Institute: Philadelphia 1985.

11 R.G. Fontaine. Reactive cognition, reactive emotion: Toward a more psychologically informed understanding of reactive homicide. - Psychology, Public Policy, and Law 14 (2008), pp. 243-261. However, see also American Law Institute (ibid.). DOI: https://doi.org/10.1037/a0013768.

12 Coroners and Justice Act 2009, Chapter 25. Available at http://www.legislation.gov.uk/ukpga/2009/25/pdfs/ ukpga_20090025_en.pdf (most recently accessed on 15.1.2018).

13 See also T. Bachmann (see Note 5) for a discussion of loss of control.

14 J. Saar, P. Pikamäe (see Note 2).

15 R.G. Fontaine, K.A. Dodge. Real-time decision making and aggressive behavior in youth: A heuristic model of responsive evaluation and decision (RED). - Aggressive Behavior 32 (2006) / 6, pp. 604-624. - DOI: https://doi.org/10.1002/ab.20150.

16 R.G. Fontaine (see Note 11). 
extreme reaction in these cases than in others, since provoking situations can initiate immediate and strong emotional responses that affect our ability to reason and thereby can lead to unlawful actions. ${ }^{*}{ }^{*}$

Historically, the term 'affect' can refer to either of two distinct states: 'physiological affect' (i.e., overwhelming emotions and behavioural responses that are not classified as a characteristic of a mental disorder per se, where this state is identified by a clinical psychologist who determines that the state is nonpathological) and 'pathological affect' (i.e., a mental state that can be classified as indicatinve of a mental disorder and thereby could indicate that the capability of guilt is absent, where this state is identified by a psychiatrist since the person assessing the state should be able to judge it pathological). ${ }^{*} 18$ Through such distinctions, affect can differ in its legal consequences in judicial settings on the basis of whether it is in line with the defining elements of an offence (PC §115), is indicative of mitigating circumstances (PC \$57 (1) 6)), constitutes a feature diminishing one's capability of understanding and guiding one's behaviour (PC \$35), or is a factor excluding the consideration of guilt (PC \$34). ${ }^{*} 19$ This creates a situation wherein, on the one hand, the act may have been committed in a provoked state but, on the other, the person's behaviour could have been disturbed in such a way that the person was rendered partially or completely incapable of guilt.

Hence, to cover all the above, the experts are often asked three questions: i) whether the person was acting in a provoked state; ii) whether the person was acting in a state of physiological affect, and iii) whether the person while committing the crime was able to understand the meaning of the act and guide his or her behaviour accordingly? ${ }^{* 20}$ Saar and Pikamäe ${ }^{* 21}$ discuss the most comprehensive answers related to provoked state as being provided via 'complex' expert assessment (that is, assessment in both psychological and psychiatric terms), since the person may be incapable of guilt.

Although provoked state is a concept used in legal terminology, no equivalent state is described in diagnostic manuals of mental disorders; one cannot be identified either in the 1oth version of the International Statistical Classification of Diseases and Related Health Problems (ICD-10) ${ }^{* 22}$ or in the $5^{\text {th }}$ edition of the Diagnostic and Statistical Manual of Mental Disorders (DSM-5) ${ }^{*}{ }^{23}$.

It is suggested that in identifying provoked state, experts assess firstly whether the defendant at the time of the offence displayed a neurotic disorder such as an acute stress reaction (which may manifest itself in various degrees of intensity and thereby create different content and duration of dysfunction in human behaviour). ${ }^{* 24}$ According to ICD-10, an acute stress reaction can be a response to 'an exceptionally stressful life event ${ }^{\prime}{ }^{*}{ }^{25}$ In the DSM-5 diagnostic system, an acute stress disorder (308.3) is defined in a similar way. ${ }^{*}{ }^{* 6}$ After this stage in the assessment, the effects of the reactions are evaluated, in terms of whether at the time of commission of the act the person was capable of understanding the unlawfulness of that act and of acting

17 S.J. Sherman, J.L. Hoffmann. The psychology and law of voluntary manslaughter: What can psychology research teach us about the 'heat of passion' defence? - Journal of Behavioral Decision Making 20 (2007) / 5, pp. 499-519. - DOI: https:// doi.org/10.1002/bdm.573.

18 J. Saar, P. Pikamäe (see Note 2). Read more of the identification issues of physiological affect also from T. Kompus (see Note 2).

19 See also J. Saar, P. Pikamäe (see Note 2); P. Randma (see Note 2).

20 P. Randma (see Note 2).

21 See also J. Saar, P. Pikamäe (see Note 2).

22 World Health Organization. The ICD-10 Classification of Mental and Behavioural Disorders: Clinical descriptions and diagnostic guidelines, 1992. Available at http://www.who.int/classifications/icd/en/bluebook.pdf (most recently accessed on 15.1.2018).

23 American Psychiatric Association. Diagnostic and Statistical Manual of Mental Disorders (5th Ed.). Washington, DC, 2013. - DOI: https://doi.org/10.1176/appi.books.9780890425596.893619.

24 T. Kompus (see Note 2).

25 According to ICD-10, an acute stress reaction is a transient disorder that develops in an individual without any other apparent mental disorder in response to exceptional physical and mental stress and that usually subsides within hours or days. The symptoms show a typically mixed and changing picture and include an initial state of 'daze' with some constriction of the field of consciousness and narrowing of attention, inability to comprehend stimuli, and disorientation. This state may be followed either by further withdrawal from the surrounding situation or by agitation and over-activity. The symptoms usually appear within minutes of the impact of the stressful stimulus or event and typically disappear within two to three days (often within hours). Partial or complete amnesia for the duration of the episode may be present.

26 The DSM-5 defines an acute stress disorder as arising from exposure to actual or threatened death, serious injury, or sexual violation manifested in one or more ways. In cases of actual or threatened death of a family member or friend, the events(s) must have been violent or accidental; symptoms from any of the categories of intrusion, negative mood, dissociation, avoidance, and arousal are present; and symptoms typically begin immediately after the trauma. The DSM-5 definition also includes the disturbance causing clinically significant distress or impairment in social, occupational, or other important areas of functioning. 
accordingly. This expert evaluation is important if one is to understand whether the person's state entailed ability to guide his or her actions (and, through this, to identify whether that person was capable of guilt or not). ${ }^{*} 27$

Kompus $^{*} 28$ emphasises that other characteristics too should be considered in examination of the defendant (e.g., a combination of cognition and behaviour that may have affected the person's thinking and behaving in the situation in question). She notes that, although emotional reactions are not controlled by volition, we can still control the behaviours we exhibit in response to emotional reactions. This notwithstanding, one's emotional reactions and their regulating effect on behaviour can still be disturbed (a fact that has been taken into consideration by legislation).

The identification of provoked state is rendered even more complicated in light of the acute-stressrelated descriptions above by the fact that it cannot be considered a mental disorder, in the case of which there may be a question of mental capacity instead. ${ }^{* 29}$ Ulväng $^{*} 30$ has noted also that manslaughter in a provoked state with a disturbed state of mind caused by sudden rage or anger cannot be considered a symptom of a mental disorder. The state impairs the person's ability to foresee long-term consequences of the behaviour; however, it should not be seen as influencing one's ability to understand the act and guide his or behaviour.

Kask and Salumäe ${ }^{* 1}$ have concluded that experts find it difficult to answer the questions specified in the expert-assessment regulations with regard to provoked state because the wording of the questions differs (the language may refer variously to identifying the presence of provoked state, physiological affect, or an acute stress disorder) and also since experts respond differently (either identifying a provoked state or noting circumstances that imply the presence of a provoked state, as the final ruling on this matter is made by the court).

Presenting related conclusions, Saar and Pikamäe note that three conditions should be met if one is to decide that there exists manslaughter committed in a provoked state (addressed in PC §115). Firstly, during the crime, the person must have been in a certain emotional state that can be described as a physiological affect. Secondly, this state has to have been provoked by the victim through his or her non-legitimate behaviour. Finally, this condition must have appeared sudden and unexpected for the defendant. Sometimes it may also be considered to have formed cumulatively: It is known that provoked state can arise over the course of a lengthy process, as in the case of repeated insults in a span of time that ends with the aggressive act of the defendant. ${ }^{*} 32$ Constant affective pressure can result in a situation wherein conflict 'takes over' the person and hence that person acts accordingly, in what has been referred to as a cumulative affect. ${ }^{*} 33$ In consideration of such factors, temporal proximity between particular provocation and the act is not as important as the fact that the act is conducted under the influence of violence or insult. ${ }^{*} 4$ Also, being in a state of alcohol intoxication cannot be deemed a factor overriding that of provoked state. ${ }^{*} 35$

An Estonian Supreme Court ruling ${ }^{*} 36$ has emphasised that provoked state is open to legal evaluation and that this state's presence can be identified by means of facts in the criminal case. The court stated that impulsiveness and unstable mood do not imply that the person in question has a diminished capability to understand his or her behaviours and to guide them. The ruling noted also that, whether or not an expert assessment is conducted, the final determination is formed as decided by the court and that there hence may be cases wherein experts are not engaged or consulted and the court makes the decision by analysing only the mitigating circumstances. The causal relationship between the provocative behaviour of the victim

27 T. Kompus (see Note 2).

28 Ibid.

29 J. Sootak, P. Pikamäe. Karistusseadustiku kommenteeritud väljaanne 4.trükk ['Commentaries to the Penal Code, 4th Edition']. Juura 2015 (in Estonian). See also P. Randma (see Note 2).

30 M. Ulväng. Rethinking 'in affect' - disturbed states of mind and criminal responsibility. - Scandinavian Studies in Law 54 (2009), pp. 165-190.

31 K. Kask, S. Salumäe. The analysis of complex forensic psychiatry and psychology expert assessments in Estonia. - Juridica International 2015/23, pp. 133-141. - DOI: https://doi.org/10.12697/ji.2015.23.14.

32 T. Kompus (see Note 2).

33 See J. Saar, P. Pikamäe (see Note 2).

34 P. Randma (see Note 2).

35 J. Saar, P. Pikamäe (see Note 2).

36 Estonian Supreme Court judgement 3-1-1-86-04, of 7 October 2004. See also Tartu Circuit Court ruling 1-14-9226, of 15 October 2015. 
and the provoked state should be established (and proved), in awareness that provocation can be longterm and systematic; therefore, separate acts should be taken into consideration as parts of a whole, and that whole should be evaluated thoroughly. In sum, the Supreme Court implied that provoked state is not a medical state identified through expert assessment but a matter for the court to ascertain. For example, an emotional reaction might arise from an erroneous interpretation. Sootak and Pikamäe ${ }^{*} 37$ indicate along similar lines that provoked state should be subject to judicial evaluation and identified on the basis of the facts of the case, with any evidence being admissible to prove the presence of that state. They conclude that, while experts may be consulted for identifying the circumstances, the findings from the assessment are not binding for the court.

\subsection{The aim for the study}

The aim behind our study was to examine how provoked state is identified in first-instance (county court) rulings in Estonia. The extent to which Estonian county courts use expert assessments from forensic psychiatry and psychology in identifying provoked state was examined for exploring whether regional differences exist in identification of provoked state. Also, we investigated whether certain factors characterising the defendant and his or her interaction with the victim(s) are associated with the determination that a provoked state is present, among them the defendant's intoxication by alcohol, the duration of the provocation, the defendant's prior convictions for criminal acts, and the defendant's relationship to the victim. Of particular interest is whether specific factors or circumstances can predict the presence of a provoked state.

\section{Methods}

\subsection{The study sample}

The sample for the study consisted of 84 county court rulings, from four court districts (Harju, Pärnu, Viru, and Tartu), rendered between 2006 and 2016. The total number of defendants in these rulings was 89, with the following breakdown: 49 before Harju County Court, eight from Pärnu County, 28 in Viru County, and four before Tartu County Court. Of the defendants, 81 (91\%) were men and eight (9\%) were women. The native language of the defendants was Estonian in 34 cases (38\%) and Russian in 55 (62\%) of them. Defendants' mean age at the time of the ruling on their case was 39.14 years (SD: 13.16, range: 15-73). The defendant had received at least some basic education in 27 cases, vocationally oriented secondary education in 20 cases, other secondary education in 13 cases, and higher education in three cases (for 26 cases, no data pertaining to education were available).

There were 55 defendants accused of one crime, 24 accused of two crimes, and 10 accused of committing three to five crimes. The defendant was primarily convicted of homicide in 48 cases, murder in 15 cases, manslaughter in a provoked state and causing serious harm to health in seven cases each, physical abuse in five of the cases, and negligent homicide in two, with one case each of conviction for abuse of authority, torture, threat, aggravated breach of public order, and non-disclosure of a criminal offence. In 81 cases, there was one victim of the crime, in six cases there were two victims, and in two cases there were three. As for the type of proceedings, 78 defendants were tried in general, four in compromise, five in alternative, and two in summary procedure. The rulings were made by 36 judges in all: 12 with Harju, five with Pärnu, 15 with Viru, and four with Tartu County Court. 


\subsection{Procedure and statistical analyses}

The rulings were retrieved from the State Gazette between 2006 and 2016 via the keywords 'state of affect', 'affect', 'provoked state', and 'stress'. The numbers of registered offences with regard to PC §113 and §115 are presented in Table $1 .{ }^{*}{ }^{8}$ Characteristics referred to in the rulings were registered and, as necessary, categorised and coded. The differences between the two groups were analysed by means of chi-squared analysis ${ }^{*} 39$ and $t$-tests for independent samples. ${ }^{*} 40$ Loglinear analysis was used to analyse predicting factors for the presence of provoked state. For all tests, $p$-values < .05 (two-tailed) were regarded as statistically significant.

Table 1: Numbers of registered offences under $\S 113$ and $\$ 115$ between 2006 and 2016

\begin{tabular}{cccccccccccc}
\hline & 2006 & 2007 & 2008 & 2009 & 2010 & 2011 & 2012 & 2013 & 2014 & 2015 & 2016 \\
\hline$\S 113$ & 107 & 90 & 88 & 64 & 62 & 81 & 59 & 50 & 42 & 38 & 35 \\
$\S 115$ & 1 & 2 & - & - & - & - & - & 1 & 1 & - & - \\
\hline
\end{tabular}

Source: Kuritegevus Eestis 2016 ['Crime in Estonia 2016'], by the Estonian Ministry of Justice.

\section{Results}

In one case, the defendant was found not guilty. In all other cases, the defendants were convicted - in three defendants' cases, the penalty was pecuniary punishment; in three, it was a life sentence; and in 82 it was imprisonment for a fixed term (for, on average, 7.46 years, $S D=3.73$, with a range of one month to 20 years).

Provoked state was identified in 15 cases, or $17 \%$ (in 13 men and two women). In 32 cases (36\%), the court evaluated the claim of a provoked state existing without resorting to expert assessments and used expert assessments for 57 defendants (64\%). The court identified a provoked state as present by means of expert assessments in eight cases (53\%) and without using expert assessments in seven cases (47\%). The absence of a provoked state, in turn, was identified by the court without expert assessments in 25 cases (34\%) and via expert assessments in 49 (66\%) of the defendants' cases. Chi-squared analysis in Fisher's exact test found no statistical difference: $\mathrm{X}^{2}(1)=.90, p=.34$, Cramer's V $=.100$.

When provoked state was identified, in 12 cases the defendant's penalty was imprisonment and in three cases it was pecuniary punishment; when provoked state was not identified, in 74 cases the defendant was imprisoned (receiving a life sentence in three cases). In cases of imprisonment, the sentence differed in line with the presence or absence of provoked state, with $t(80)=3.85, p=.001$ (in years, presence $M=3.73$, $S D=2.43$; absence $M=8.04, S D=3.57$ ).

\subsection{Differences by region}

As both Tartu and Pärnu County Court had relatively few cases (four and eight, respectively), differences only between Harju and Viru County Court were compared by means of chi-squared analysis in Fisher's exact method. Firstly, differences between county courts in whether provoked state was identified in court procedures involving expert assessments or instead by the court on its own were examined (see Table 2). The results demonstrate that Harju County Court requested expert assessments more often than did Viru County Court, with $\chi^{2}(1)=17.09, p=.001$, Cramer's V $=.471$. Next, the differences in identifying the presence of a provoked state were compared at county court level (these results too are shown in Table 2). Harju and Viru County Court did not differ significantly: $\chi^{2}(1)=1.38, p=.24$, Cramer's V $=.134$.

\footnotetext{
38 Ministry of Justice. Kuritegevus Eestis 2016 ['Crime in Estonia 2016']. Available at http://www.kriminaalpoliitika.ee/ sites/krimipoliitika/files/elfinder/dokumendid/kuritegevus_eestis_est_web_0.pdf, in Estonian (most recently accessed on 2.6.2018).

39 To analyse the differences between proportions.

40 To analyse the differences between groups.
} 
In Harju County Court, the defendants who were identified to have been in a provoked state were convicted of manslaughter in a provoked state (under PC §115) in five cases (two in general, two in compromise, and one in alternative procedure) and of attempted manslaughter (PC §113 in connection with §25 (2)) in two cases (both applying general procedure). In Viru County, one defendant was convicted in compromise procedure of manslaughter in a provoked state under $\S 115$, one of causing serious harm to health under $\S 118$ (in general procedure), three of physical abuse under $\S 121$ (two in general and one in summary procedure), and one of torture under $\S 290$ (in general procedure), while one was found not guilty of abuse of authority under §291 (in general procedure).

Table 2: Absolute and percentage figures for presence of expert assessments and of provoked state, by county court

\begin{tabular}{llllc}
\hline County & EA & $\boldsymbol{N}(\%)$ & PS & $\boldsymbol{N ~ ( \% ) ~}$ \\
\hline \multirow{2}{*}{ Harju } & Yes & $39(80 \%)$ & Yes & $7(14 \%)$ \\
& No & $10(20 \%)$ & No & $42(86 \%)$ \\
\multirow{2}{*}{ Viru } & Yes & $9(32 \%)$ & Yes & $7(25 \%)$ \\
\hline \multirow{2}{*}{ Pärnu } & No & $19(68 \%)$ & No & $21(75 \%)$ \\
\hline \multirow{2}{*}{ Tartu } & Yes & $6(75 \%)$ & Yes & o (0\%) \\
& No & $2(25 \%)$ & No & $8(100 \%)$ \\
\hline
\end{tabular}

Note. 'EA' = presence of expert assessment; 'PS' = presence of provoked state.

In further analysis, the differences in identification of the presence of provoked state and in commissioning of expert assessments were compared between county courts (see Table 3). For cases wherein a provoked state was identified, a statistically significant difference emerged. Namely, expert assessments were ordered in all the cases before Harju County Court, whereas the corresponding cases heard by Viru County Court involved no expert assessments being sought, with $\chi^{2}(1)=14.00, p=.001$, Cramer's V $=1.000$. Also when a provoked state was not identified, a statistically significant difference was found: in $76 \%$ of these cases before Harju County Court, expert assessments were obtained, whereas for nearly half of the Viru County Court cases there were no expert assessments commissioned, $\chi^{2}(1)=6.85, p=.01$, Cramer's $\mathrm{V}=.33$.

Table 3: The total case counts and percentages for presence and absence of provoked state, by county court

\begin{tabular}{lccccc}
\hline & EA & Harju & Tartu & Viru & Pärnu \\
\hline \multirow{2}{*}{ Provoked state present } & Yes & $7(100 \%)$ & $1(100 \%)$ & - & - \\
& No & - & - & $7(100 \%)$ & - \\
\hline \multirow{2}{*}{ Provoked state absent } & Yes & $32(76 \%)$ & $2(34 \%)$ & $9(43 \%)$ & $6(75 \%)$ \\
& No & $10(24 \%)$ & $1(67 \%)$ & $12(57 \%)$ & $2(25 \%)$ \\
\hline
\end{tabular}

Note. 'EA' = presence of expert assessment.

It was also of interest whether differences in use of expert assessments existed between judges. The level of usage of expert opinions was coded into five categories on the basis of the distribution of the cases for the given judge: always referring to experts ( $n=16,44 \%)$, using expert assessments in most cases $(n=5,14 \%)$, showing rough equality between use and non-use of experts $(n=5,14 \%)$, mostly not using experts $(n=1,3 \%)$, and never engaging experts $(n=9,25 \%)$.

There were more judges who resorted to experts in all or most cases than judges who did not, with $\chi^{2}(4)=17.89, p=.001$, Cramer's $V=.329$. When the Harju and Viru county court were compared (see 
Table 4), almost $83 \%$ of judges in the former jurisdiction were found to have always or in most cases used experts, whereas the equivalent proportion in Viru County Court was only $34 \%$ ( $52 \%$ of judges never used experts), with $\chi^{2}(4)=11.34, p=.01$, Cramer's $V=.648$.

Table 4: Judges' total case counts and percentages for engaging expert assessments, by county court

\begin{tabular}{lcccc}
\hline & Harju & Tartu & Viru & Pärnu \\
\hline All cases & $N(\%)$ & $N(\%)$ & $N(\%)$ & $N(\%)$ \\
Most cases & $6(50 \%)$ & $3(75 \%)$ & $4(27 \%)$ & $3(60 \%)$ \\
Half of cases & $4(33 \%)$ & - & $1(7 \%)$ & - \\
Under half of cases & $2(17 \%)$ & - & $1(7 \%)$ & $2(40 \%)$ \\
No cases & - & - & $1(7 \%)$ & - \\
\hline
\end{tabular}

\subsection{The defendant-victim relationship}

The relationship between the defendant and the victim(s) was coded into three categories on the basis of the information in the rulings: family members, acquaintances, and strangers. Where a provoked state was found to be present, the victim was a family member of the defendant in three (20\%) of the cases, his or her acquaintance in seven cases (53\%), and a stranger to the defendant in four (27\%) cases; when a provoked state was deemed absent, the victim was a family member in 15 cases (19\%), an acquaintance in $45(56 \%)$, and a stranger in 14 (25\%). There were no differences in the relationship between the defendant and the victim(s) between cases with the presence versus absence of a provoked state, $\chi^{2}(2)=.78, p=.78$, Cramer's V = .049.

\subsection{Duration of the conflict}

From the rulings, the duration of the conflict between the victim(s) and the defendant was coded into two categories on the basis of whether it involved a one-off episode or instead two or more episodes. A nonsignificant difference emerged: $\chi^{2}(1)=.25, p=.70$, Cramer's $\mathrm{V}=.053$. When a provoked state was present, in 12 (75\% of) cases the conflict involved a single episode, whereas when a provoked state was not considered present a one-off incident had occurred in 63 (83\% of) cases; the comparative figures for two or more episodes are three (25\%) and 11 (13\%) cases, respectively.

\subsection{Intoxication by alcohol}

In 70 cases, the defendant was intoxicated by alcohol, in 17 cases he or she was sober, and in two cases the ruling did not state whether the person was intoxicated or not. There was a significant difference with regard to intoxication by alcohol and provoked state, with $\chi^{2}(1)=5 \cdot 77, p=.027$, Cramer's V =.258; namely, in four of the 14 cases in which a provoked state was identified (or 29\%), the defendant was intoxicated, whereas when a provoked state was not found to be present, 62 out of 73 defendants (or 85\%) were intoxicated.

\subsection{Previous criminal convictions}

There were previous criminal convictions present in 45 cases (range: 1-14 convictions) and not present in 38 cases. There were no data for six defendants. A significant difference emerged: out of 14 defendants in a provoked state, four (29\%) had prior convictions, whilst of the 69 defendants for whom a provoked state was not deemed present, 41 (59\%) had prior convictions, with $\chi^{2}(1)=4.46, p=.043$, Cramer's V =.232. 


\subsection{Predicting the presence of a provoked state}

In addition, five-way loglinear analysis was performed (presence of provoked state $\times$ relationship between the defendant and the victim(s) $\times$ duration of the conflict $\times$ intoxication by alcohol $\times$ previous criminal convictions) to test whether the presence of a provoked state can be predicted by any of these factors. This loglinear analysis produced a final model that retained all effects, but no factors proved significantly able to predict the presence of a provoked state.

\section{Discussion}

Our research was conducted to examine how provoked state is identified from the perspective of county court rulings in Estonia. When looking at whether it is identified solely by the court or by the court engaging expert assessments in the fields of forensic psychiatry and psychology, we found that provoked state was concluded to exist in 15 out of the 89 cases identified and that expert assessments were used in two thirds of these cases. There were no significant differences in whether expert assessments were used between when said state was identified and when it was not - in half of the cases wherein provoked state was identified, expert assessments were used, whereas two thirds of the cases in which a provoked state was found to be absent involved expert assessments.

Although Harju County Court requested expert assessments more often than Viru County Court did, the level of presence of provoked state found did not differ. When provoked state was identified, all seven of the relevant cases before Harju County Court referred to expert assessments, whereas there were seven Viru County Court cases in which no expert assessments were used for its identification. A similar trend was present, albeit of lesser magnitude, for cases wherein a provoked state was not identified by the court. The cause of this difference remains unclear and should be examined more closely in future work.

Also, our study investigated whether some factors pointed out in court rulings were associated with the presence of a provoked state. It was found that there was no evident association between the presence of provoked state and the duration of the conflict, nor an association with the relationship between the defendant and the victim(s). This may indicate that provoked state can emerge in very different situations and circumstances. ${ }^{*}{ }^{41}$ That said, there were differences in intoxication by alcohol (when provoked state was found, the defendants were intoxicated in fewer cases) and related to previous criminal-court convictions (those defendants found to be in a provoked state had fewer previous criminal convictions). It must be stated that the presence of provoked state is individual- and situation-dependent; therefore, it is not justifiable to reason that if a defendant has a prior conviction for criminal offences and is intoxicated by alcohol then the probability of the presence of provoked state is low. This conclusion is supported by the results of our loglinear analysis wherein no factors were predictive of the presence of a provoked state. The findings indicate that human behaviour can vary over a broad spectrum by situation and circumstances. ${ }^{*} 42$ Hence, an expert assessment can add useful non-legal knowledge to the court's picture for in forming just rulings.

A large proportion of judges used expert assessments. However, almost four fifths of Harju County judges did so in all or most cases whereas nearly half of the ones in Viru County never did. It is difficult to say why these differences occur - whether the difference is due to specific cases in the county, lack of experts to engage, or other factors. Whatever the reasons, it must be acknowledged that, by decision of the Estonian Supreme Court, the court is independent in taking into consideration violence or insult directed at the defendant or one or more persons close to him or her, and also that provoked state is not only a medical notion identifiable in corresponding terms during the course of expert assessment but also something that can be identified by evaluation of the actions of the victim(s) toward the defendant. ${ }^{*} 3$ Provoked state is a state whose identification necessitates not merely a sudden change in human behaviour having appeared. One must establish in addition that the victim(s) insulted the defendant and/or his or her relatives. ${ }^{*} 44$ Hence, it may be that these circumstances are clear enough for the court in certain cases. Nonetheless,

\footnotetext{
See R.G. Fontaine (see Note 11).

T. Kompus (see Note 2).

CLCSCd 3-1-1-86-04 - RT III 2004, 25,273.

See J. Saar, P. Pikamäe (see Note 2).
} 
it would still be of interest to examine more closely the motivation behind the decision to not use expert assessments in these cases.

In Harju County Court proceedings, the seven defendants identified as having been in a provoked state were convicted in most cases either of homicide or of manslaughter in a provoked state, under various procedural forms (general, compromise, and alternative procedure). In Viru County Court, however, only one of the seven corresponding defendants was convicted of manslaughter in a provoked state. The factors behind the differences between county courts in identifying the presence of provoked state are worthy of further study. As can be seen, there is a slight difference in types of crimes between those two county courts, so one cannot readily determine whether the two county courts do their work differently or, rather, the differences stem from processing of different crimes. Therefore, this issue should be examined more closely in the future if we are to ensure that criminal proceedings are carried out in a similar manner from one court district to the next.

One limitation to be pointed out is that only a few court rulings involving issues of provoked state were issued by the Pärnu and Tartu county courts. This made examination of region-linked differences possible only between the Harju and Viru county courts.

The findings can be summarised thus: In two thirds of cases, forensic psychiatry and psychology experts were used in assessing the presence of provoked state. Region-linked differences were seen in identification of this state. As for predictive factors, alcohol intoxication and previous criminal convictions were correlated with the presence of a provoked state, whereas the duration of the conflict and the relationship between the defendant and the victim(s) were not. 